\title{
Persistent Disease
}

National Cancer Institute

\section{Source}

National Cancer Institute. Persistent Disease. NCI Thesaurus. Code C90169.

A disease that does not go to remission despite treatment. 